\title{
Strategic management in retail pharmacy: The case of Zimbabwean companies
}

\author{
Amon Simba and Zivanayi Nyandoro \\ Nottingham Business School, Division of Management, Nottingham Trent University United Kingdom.
}

Received 16 January, 2016; Accepted 18 March, 2016

\begin{abstract}
Retail pharmacies operating in developing and emerging nations are faced with a myriad of intractable macro-economic conditions including over-regulation, government interference, inept policy implementations and intensive competition. These conditions demand that retail pharmacies become strategic in their approach to business management in order to diminish the impact of macro-economic conditions conspiring to influence their performance in the market. From that perspective, this study investigates the specific strategic management approaches employed by retail pharmacies in Zimbabwe to navigate the country's harsh economic conditions. In order to examine their management approaches, a questionnaire survey consisting of 90 retail pharmacies was carried out. Data collected from the survey was analysed using regression analysis. From this, the study developed a nuanced strategic management model that can be applied in managing businesses operating in unpredictable markets either in developing, emerging or advanced nations.
\end{abstract}

Key words: Developing and emerging nations, retail pharmacies, strategic management, macro-economic conditions

\section{INTRODUCTION}

Operating and managing a business in a developing or emerging economy demands dynamic and high level strategic management capabilities. Extensive market regulation, inept policy implementation, hypercompetition and government interference are common features in most developing or emerging economies. In Zimbabwe, a country of focus in this study, government interference in the pharmaceutical manufacturing and retail pharmacy markets, in particular, and the economic environment, in general, significantly influence business operations and management.

In an attempt to control the pharmaceutical sector through extensive market regulations and policy implementation, the Zimbabwe government only succeeded in forcing world renowned pharmaceutical companies to cease operating in the country. The closures at Central Admixture Pharmacy Services (CAPS) (Pvt) Ltd and Wallace Laboratories are well-documented events demonstrating the impact of a government's ill-conceived policy for indigenisation termed the 'Black Indigenisation' agenda (Deloitte and Touché, 2013). Although this (Black Indigenisation) was done to stimulate organic growth; the sudden pressure on retail pharmacies to provide essential health services to meet customer demands was immense However, the Black Indigenisation policy gave both private and state-owned retail pharmacies the impetus

*Corresponding author. E-mail: amon.simba02@ntu.ac.uk.

Authors agree that this article remain permanently open access under the terms of the Creative Commons Attribution License 4.0 International License 
to exploit the opportunities it created (Criminal Investigation Agency (CIA) World Fact Book, 2012). As a direct consequent of this, there was a surge, in numbers, of retail pharmacies vying for market share in a country with customers whose purchasing power had been severely eroded by a malfunctioning economy, heavily controlled by politicians and on the brink of collapse. This market system created a sternly challenging combination of macro-economic conditions whereby relying on traditional tactics for selling pharmaceutical products was less effective. This meant that retail pharmacies had to be strategic in their business approaches. Therefore, in order to understand their strategic approaches in the pharmaceutical sector in Zimbabwe, this study addresses the following key questions:

1. How do retail pharmacies in Zimbabwe identify business opportunities in the country's pharmaceutical sector?

2. Which operations and management strategies have they adopted to enhance their market performance and survival in Zimbabwe?

3. How effective are their business methods?

To address the earlier stated questions, the study explores theinterplaybetweenstrategizing, entrepreneuring, change and investing as the key determinants of enhanced market performance and business survival in unpredictable market conditions. In doing so, the study provide useful knowledge regarding the most appropriate business strategies managers operating in harsh macro-economic conditions often a common feature in most developing and emerging markets could adopt. This is refreshing considering that existing strategic management concepts/ models fall short of representing the specific approaches to business management in developing and emerging economies. The research study contributes to the discourse on strategic management in developing and emerging economies.

\section{LITERATURE REVIEW}

The process of developing an effective business model is so complex and multi-dimensional and yet it is a key catalyst for survival and better market performance in markets that are constantly evolving. It is therefore imperative that businesses operating in such complex and unstable market conditions recognise strategic planning as a key strategic management function (Desai, 2000).

According to Kuratko and Audretsch (2009) strategic planning 'is the formulation of long-range plans for the effective management of environmental opportunities and threats in light of a business's strengths and weaknesses'. Consistent with this, Hitt et al. (2011) explained that strategic planning should encompass an organisation's mission clearly highlighting achievable objectives, developing strategies, and setting policy guidelines. Evidently, the literature on strategic planning is littered with evidence emphasising that strategic management enables entrepreneurial businesses to:

1. Deal with causal effects and provide possible solutions.

2. Understand their macro-economic environment.

3 . Define the purpose of the business.

4. Clarify the motives, values and resource-requirements of the business (Scarborough, 2014; Goncalves, 2009; Mazzarol et al., 2009; Mason, 2007; Mintzberg, 1987; Stacey, 1995).

Consistent with this, Sandada et al. (2014) and Normann and Ramfrez (1993) agree that effective strategic planning underpins the management process responsible for creating stability in a business particularly in unstable markets. While complexity and market turbulence can be anticipated, many businesses often lack a plan of how to cope in such conditions; it therefore makes more sense to find ways of handling such situations (Mason, 2007). Inspired by the study observations of Zimbabwe's pharmaceutical sector, the study argue that strategic planning as a function of management must form the foundations of any attempt for better market performance in volatile market. The strategic plan should cover entrepreneuring, strategizing, changing and investing processes

\section{Operationalizing the concept of strategic management}

The concept of strategic management within the discipline of business management and strategy has generated huge interest from management scholars who have looked at it from different angles. Some scholars have placed emphasis on rethinking strategic planning as well as on the strategic intent of an organisation to capture the essence of winning (Prahalad and Hamel, 1989; Mintzberg, 1994; Johnson et al., 2008; Ansoff and Sullivan, 1993). Others have conceptualised strategic management as an important business approach needed in today's dynamic and highly unpredictable business environments (Hamel, 1996; Anderson and Atkins, 2001; Al-Shaikh, 2001; Mazzarol et al., 2009; Hitt et al., 2011; De Wit and Meyer, 2014). In Larsen et al. (1998) a different definition encompassing the strength and weaknesses of a company and potential opportunities as platforms for developing its future growth strategies was adopted. Kraus et al. (2007) viewed strategic planning as a process of strategic management arguing that it is an attempt to prepare future contingencies to account for environmental dynamics and complexities.

Taking into account the multi-faceted dimension of the concept of strategic management, the study combine 
more than one perspective and focus on strategizing, entrepreneuring, changing and investing as the key determinants for survival, economic prosperity and better performance in chaotic markets.

\section{Strategizing}

In unstable macro-economic conditions effective companies can be identified by their desire to exploit the unfolding opportunities and their preparation for potential threats (Porter, 1985). A number of studies universally acknowledge that dealing with problems of a strategic nature requires top management teams (TMTs) to go through a strategic reasoning process searching for ways to define and resolve problems at hand (Barney, 1991; Mintzberg, 1994; Teece et al., 1997; Picken and Dess, 1996; Adner and Helfat, 2003).

In Fraser and Stupak (2002) study strategizing is conceptualised as a way of ensuring clarity of goals, communication of strategic intent and more importantly, the development of a plan for responding to the business environment. Clearly, the underlying thesis is that it is of paramount importance that businesses operating in fragile market conditions continue to align/renew their business processes to enhance their prosperity (Sandada et al., 2014). Similarly, Johnson et al. (2008) commented that in a changing environment, organisations should be clear about their direction and scope over a long-term period.

\section{Hypothesis 1}

Strategizing is an essential strategic management capability which helps in formulating a vision for the future success of an organisation while anticipating changes in the macroeconomic environment.

It would however be naïve to assume that strategizing is the panacea to solving a myriad of challenges for managing an organisation in chaotic markets. Careful consideration should be given to the position of the company in the market to avoid strategic drift (Johnson et al., 2006) which may have an impact on survival, economic prosperity and better performance. In the literature (Johnson et al., 2008; Mason, 2007; Eisenhardt and Sull, 2001; Hamel, 2000; Prahalad and Hamel, 1989) there is consensus that managers should develop strategies that are appropriate to the specific macroeconomic conditions facing their firms.

\section{Entrepreneuring}

The importance of being entrepreneurial among strategy managers is widely recognised as the driving force for creating new markets and for establishing new positions in existing markets as well as for creating new order from the old (Hamel and Prahalad, 1995; Markides, 1999; Shane, 2000; Shane and Venkataraman, 2000; De Wit and Meyer, 2014; Kuratko, 2014). Linking entrepreneurship with uncertainty Knight (1921) explained that uncertainty is an unavoidable aspect of the entrepreneurial management phenomenon. This is can be true for organisations operating in fast-moving market conditions. Coping with uncertainty should be part of demonstrating resilience in entrepreneurial organisations (Burns, 2012). Any wrong strategic choices by the top management teams may have devastating consequences (Hamel and Prahalad, 1995). Notwithstanding this, Kuratko and Audretsch (2009) regarded entrepreneurship as a dynamic process of vision, change, and creation in challenging market conditions. As far as the discourse concerning entrepreneurship goes Kirzner's (1973) dated yet still influential conceptualisation of the entrepreneurial phenomenon provided a useful starting point. Kirzner (1973) explained that an entrepreneur is someone who is alert to opportunities and creates a vehicle to exploit them.

Adding to this Hitt et al. (2001) view entrepreneurial strategy as a course of action taken by strategy managers with a view to adapt to environmental changes in order to take advantage of the opportunities arising from uncertainty and discontinuities in wealth creation. A convincing argument regarding entrepreneuring was made in Sarasvathy (2001). Sarasvathy (2001) put forward the notion that, 'successful entrepreneurs have long created firms, industries, and even economies by matching up the offspring of human imagination with human aspirations' (2001).

This is an unquestionable endorsement that visioning, inspiration and protracted determination can be vital for economic prosperity. Consistent with this Dess et al. (1997) discussed the idea of entrepreneurial strategymaking. Dess et al. (1997) agreed that entrepreneurial strategy-making comprises a collection of activities within an organisation with a view to formulating their strategic mission and future goals. Hart (1992) shared similar views but went as far as outlining the activities including: strategic planning, strategic decision-making and entrepreneurial firms should be engaged in to achieve economic prosperity. In their contribution to this debate Lumpkin and Dess (1996) argued that there is a significant link between entrepreneurial-orientation (EO) with better performance.

\section{Hypothesis 2}

An entrepreneurial minded manager is fundamental to the survival and the performance of an organisation that is faced with a myriad of challenges in markets characterised by uncertainty.

Admittedly, the entrepreneurial environment is highly 
unpredictable and inherently chaotic (Gleick, 1987). This implies that the connectivity of various components of strategic management is stochastic. As such, entrepreneurial organisations are likely to favour the intricate combination of aspects of strategizing, entrepreneuring, changing and investing. The last word on entrepreneuring can be left to Anderson and Atkins (2001) who provided useful advice which entrepreneurial firms cannot afford to dismiss. Anderson and Atkins (2001) explained that entrepreneurial firms should be aware of the fallacy of misplaced reliance on forecasts and prepare strategies that reflect a mind-set that is open to change'.

\section{Changing}

In fast-moving macro-economic conditions, it is necessary for strategy managers to continue adjusting/modifying various internal business configurations to align with the immediate surroundings. Change management is a concept well-represented in the strategic management literature (Stacey, 1995; Mintzberg and Waters, 1985), management and organisational behaviour scholarship (Mullins, 2005). These management domains are increasingly being studied alongside entrepreneurship and strategy (Katila et al., 2012; Santos and Eisenhardt, 2009; Companys and McMullen, 2007; Hitt et al., 2001; Mosakowski, 1998) showing their interconnectedness. Kuratko and Audretsch (2009) made more sense of this by proposing a new term 'Strategic Entrepreneurship' which they argued represents the intersection of strategy and entrepreneurship. This presumed linkage permits entrepreneurial firms to influence (manage and control) the configuration of individuals in the firm and shape their behaviours (culture) with a view to facilitating an entrepreneurial business model. Clearly, developing a system within the organisation has more to do with strategic management especially, the re-organisation of the key individuals/units/process in it in such a way that they collectively influence economic prosperity and better organisational performance. In a literature-based study by Companys and McMullen (2007), it was explained that organizational re-structuring is an important developmental step which significantly aids economic prosperity in organisations facing intractable challenges prolonged by constantly changing market conditions.

Adding to the discourse about business re-structuring for economic development Mullins (2013) commented that culture reduces complexity and uncertainty by facilitating a sense of shared responsibility. Similarly, Johnson et al. (2006) proposed the cultural web paradigm highlighting its usefulness towards understanding desirable culture within an organisation. Culture manifests itself in organisational values, routines, rituals and norms.

According to Mullins (2005) culture provides the basic ingredients that are necessary for enhanced organisational performances and strategy managers should champion the implementation of acceptable behaviour in their organisations.

\section{Hypothesis 3}

Strategy managers should develop business systems that are underpinned by common values, beliefs, routines and norms. They should outline current and future desired behaviour to assist economic prosperity in chaotic market conditions. Crucially, building flexibility within their businesses allows entrepreneurial individual to respond timely to changes in harsh market conditions while enabling better overall performance.

The entrepreneurial activity of an individual in an organisation is dependent on an established organisational culture and management style. Strategy managers in entrepreneurial organisations should develop and communicate their vision, scope and direction, choose quality individuals and build an entrepreneurial architecture (structures, systems and culture) for their organisations (Singer et al., 2009; Morris et al., 2008). This is especially important as a plan for responding better to the challenges synonymous with chaotic markets.

\section{Investing}

Investing in key strategic resources enables strategy managers to renew their business processes in anticipation of the future. Making the right investment decisions is a crucial part of strategic management in entrepreneurial firms as it shapes managerial and strategic destiny (Wiltbank et al., 2009). Indeed, strategic planning involves, to a greater extend, choices concerning resource-related investments to achieve corporate goals (Bowan and Hurry, 1993) while accounting for some degree of uncertainty in the process. The resourceinvestments and unfolding strategy choices are inversely related determinants of enhanced firm performance, economic growth and development (Penrose, 1959). Bowan and Hurry (1993) extended this by suggesting that invested resources can be the launch pad for an organisation's strategy.

In a related study, Gunther and Nerkar (2004) explained that investing in real options can allow organisations to gain access to opportunities markets offer than they would if their investments took the form of a full scale launch. Similarly, Kogut and Kulatilaka (1994) commented that the use of platforms as investment options is a valuable approach in the sense that it mitigates the risks associated with uncertainty and time dependency. Consistent with this, Bowan and Hurry (1993) and Dixit (1992) acknowledged that applying the investments option lens as a tool for strategic management offers an economic logic that underpins the notion of incremental resource investments. Investment appraisal methods 
Table 1. The position of the key participants in their retail pharmacy.

\begin{tabular}{lcccc}
\hline Variable & Frequency & Percentage (\%) & Valid Percentage (\%) & Cumulative percentage (\%) \\
\hline Owner & 22 & 33.8 & 33.8 & 33.8 \\
Manager & 38 & 58.5 & 58.5 & 92.3 \\
Locum pharmacist & 9 & 13.8 & 13.8 & 106.1 \\
\hline
\end{tabular}

should capture the components of flexibility and strategic value as they may significantly contribute to the firm's economic development in unstable markets (Smit and Trigeorgis, 2004).

\section{Hypothesis 4}

Strategy managers should routinely engage in making strategic investments with a degree of flexibility. Their effective allocation of resources on key projects is fundamental to a company's economic prosperity and survival in turbulent markets

Generally, investments that promise to generate returns in the long term are riskier, especially in volatile markets, than short-term options making them harder to take (De Wit and Mayer, 2014). Investing in a long-term strategic position attached to anticipated better performance and economic prosperity involves a high degree of uncertainty about the expected effects as the macro-economic conditions continue to evolve. This therefore makes committing huge amounts of resources to achieve strategic goals (economic prosperity, survival and better performance) both riskier and more uncertain given the unpredictability of today's markets both in developing and developed nations.

\section{METHODOLOGY}

The main purpose of this study was to explore the strategic management approaches adopted in retail pharmacies operating in a developing nation, and to formulate a new concept (business model) to be used as a strategic tool for survival, economic prosperity and better performance in unstable macroeconomic conditions. From that perspective, the study can be described as explanatory by design. Designing the study this way enabled the study to explain the considered impact of strategic management in unstable markets such as those found in Zimbabwe. Lewis and Saunders (2012) described the connection as 'cause-and-effect relationships'.

Therefore, to explain this occurrence it was deemed appropriate to utilise both quantitative and qualitative research methods. As such, a triangulation of research methods was adopted for data collection, and it included a review of the existing literature, structured field observations and survey questionnaires. An indepth literature review (Creswell, 2014) was used to identify the key components that militate strategic management including: strategizing, entrepreuring, changing and investing. This assisted us to construct four hypotheses as presented in the subsets of section two. These were then tested using regression analysis providing us with additional insights into the effectiveness of the strategic management approaches adopted in retail pharmacies operating in Zimbabwe.

To ensure that data collected using questionnaires was relevant, structured questions were focussed on the key variables (themes) (Bellamy and Perri, 2009; Creswell, 2014) outlined earlier as the key components of strategic management. Electronic questionnaires were also used at the data collection stage. The technique facilitated access to a large number of suitable participants. The research sample consisted of 90 retail pharmacies predominantly based in Harare the capital city of Zimbabwe. The total number of pharmacies operating in the city centre is currently 233 with a margin for error.

The sampled pharmacies were divided into four groups Central Business District (CBD), High Density (HD), Medium Density (MD) and Low Density (LD). LD has a total of 18 pharmacies which are few and as such, it was fused to make one strata with those operating in the MD. Simple random sampling was used to choose 35 pharmacies for each stratum. Thirty-five (35) questionnaires were then distributed to each of the three groups CBD, HD, LD and MD to make a total of 105 questionnaires. Out-off the 95 returned questionnaires only 90 were usable.

Ninety percent $(90 \%)$ is a high response rate which is acceptable in studies that incorporate quantitative methods (Field, 2013). The high response rate can be attributed to the keen interest and enthusiasm that most of the key participants had in this study as it was about presaging their stalwartness in dealing with market uncertainty. The demographic data representation for this study is presented in terms of the position of the participants in their selected organisations. Table 1 presents the positions of the key informants in their pharmacies. From the data on the Table 1 it can be established that the highest number (38) of participants were pharmacists and were in managerial positions, the owners of founders of the selected pharmacies were 22, and those pharmacists working on contacts of up to 12 months termed locums were only 9.

Structured field observations are prevalent in studies within the marketing discipline. In this study, structured field observations were used for surveillance and fact-finding purposes (Lewis and Saunders, 2012). The method gave us an opportunity to learn more about retail pharmacies in Zimbabwe. More so, structured field observations were chosen with the view to complementing the literatures in chapter two. Furthermore, structured field observations enabled the study to observe the activities of the pharmacies and the macroeconomic conditions they face in Zimbabwe.

\section{FINDINGS}

The study aims to develop an understanding of the importance of strategic management in developing nations. Beyond that, a nuanced business management model was developed for use in chaotic and unpredictable markets in which sustainable business development is presumed to be anchored on strategic management (Figure 1). The research study found that 


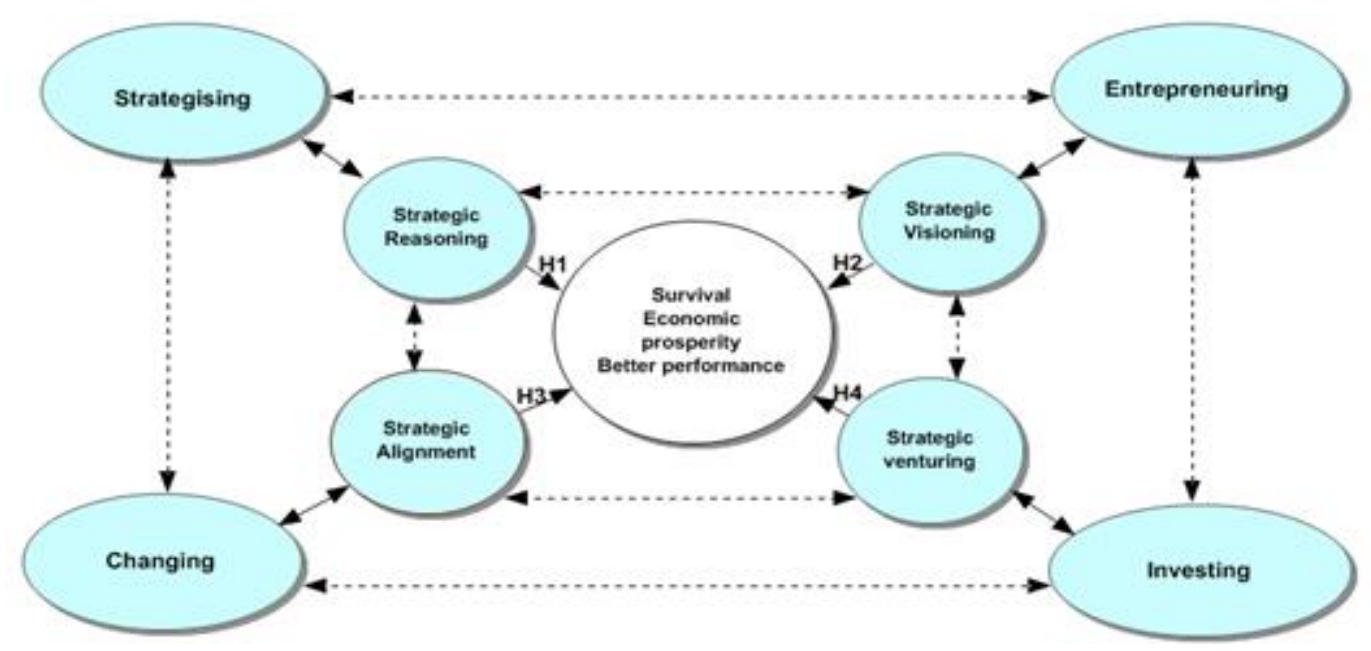

Figure 1. A new strategic management model for organisations intending to withstand/survive unstable macro-economic conditions

Table 2. The impact of strategic management in unstable macro-economic conditions.

\begin{tabular}{|c|c|c|c|c|c|}
\hline Variable & $\mathbf{N}$ & Minimum & Maximum & Mean & Standard deviation \\
\hline $\begin{array}{l}\text { How important is planning ahead, in your business to your } \\
\text { survival, economic prosperity, and better performance in the } \\
\text { pharmaceutical sector? (Strategizing) }\end{array}$ & 3 & 3 & 80 & 28.33 & 44.747 \\
\hline $\begin{array}{l}\text { How important is anticipating the future market conditions to } \\
\text { your to survival, economic prosperity, and better performance } \\
\text { in the pharmaceutical sector? (entrepreneuring) }\end{array}$ & 4 & 2 & 75 & 22.50 & 35.180 \\
\hline $\begin{array}{l}\text { How important is adjusting or modifying your internal } \\
\text { business structures to your survival, economic prosperity, } \\
\text { and better performance in the pharmaceutical sector? } \\
\text { (changing) }\end{array}$ & 4 & 2 & 78 & 22.50 & 37.063 \\
\hline $\begin{array}{l}\text { How important is making the right resource investment } \\
\text { decision, in your business for survival, economic prosperity, } \\
\text { and better performance in the pharmaceutical sector? } \\
\text { (investing) }\end{array}$ & 4 & 1 & 85 & 22.50 & 41.677 \\
\hline Valid n (listwise) & 3 & - & - & - & - \\
\hline
\end{tabular}

most of the retail pharmacies in Harare were aware of the conditions in their macro-economic environment, and they were determined to 'make it happen' for their businesses. When responding to a survey question regarding business operations-related challenges encountered in Zimbabwe, a third $(77 \%)$ of the participants indicated that the economic climate was not conducive. The same number identified forecasting, anticipating and planning as key to their businesses and they were determined to improve the positions of their companies in the market.
From this, one cannot be judged to be out of context by claiming that these retail pharmacies are applying strategic management techniques specific to developing and emerging nations. Table 2 provides a summary of the views of all the participants on the subject of strategic management. Specifically, the table highlights that a significant proportion of those who responded to the questions relating to strategy formulation felt that strategic management was key to their survival, economic prosperity and better performance in the pharmaceutical sector in Zimbabwe. A mean average of 24 on aggregate, 
Table 3. Correlation between survival, economic prosperity, better performance and strategic management.

\begin{tabular}{ccccc}
\hline Model & R & R square & Adjusted R square & Standard error the estimate \\
\hline 1 & $0.995^{\text {a }}$ & 0.989 & 0.979 & 6.341 \\
\hline
\end{tabular}

aPredictors: (constant), strategizing, entrepreneuring, changing and investing.

Table 4. The significance of association between survival, economic prosperity, better performance and strategic management.

\begin{tabular}{lccccc}
\hline Model & Sum of squares & df & Mean square & F & Sig. \\
\hline Regression & 3741.795 & 1 & 3741.795 & 93.067 & $0.00^{\mathrm{b}}$ \\
Residual & 40.205 & 1 & 40.205 & - & - \\
Total & 3782.000 & 2 & - & - & - \\
\hline
\end{tabular}

Dependent variables: survival, economic prosperity and better performance; Predictors: (constant0, strategizing, entrepreneuring, changing and investing.

indicated that strategic management involving the key components of strategizing, entrepreneuring, changing and investing is an essential capability that can 'make it happen' for businesses operating in harsh market conditions. There were no significant variations regarding the importance of strategic management in their market.

To test the four hypotheses developed, regression analysis was carried out by running simple regression. Significant evidence confirming a strong correlation between strategizing and survival, economic prosperity and better performance in the pharmaceutical sector in Zimbabwe was there. Tables 2 and 3 illustrate the value for $\mathrm{R}$ and $\mathrm{R}^{2}$ for the model that has been derived. For these data, $R$ has a value of 0.995 representing the simple correlation between survival and the key components/determinants of strategic management. The value of $R^{2}$ is 0.989 demonstrating that strategizing, entrepreneuring and advertising can account for $98.9 \%$ of the variation for surviving in harsh macroeconomic conditions.

In other words, this explains the importance of strategic management in a typical pharmaceutical market found a developing nation, Zimbabwe. Only a small percentage of about $1.1 \%$ cannot be explained by strategic management alone. There may well be other variables which were not accounted for in the study survey. In Table 3 the most important reading that helps us to understand the significance of the determinants of strategic management essential for survival in Zimbabwe is the $F$ ratio which is calculated using the equation (8.9) and the associated significance of the generated F-ratio (Field, 2013). For these data, $F$ is 93.1 which is significant at $p<$ 0.001 because the value for Sig. is less than 0.001 as illustrated on Table 3 . The results shown earlier denote that there is less than a 0.1 chance that an F-ratio this large would occur if the null hypothesis were true.
Therefore, the study can conclude that regression model results in significantly better predication of the impact of strategizing on survival, economic prosperity and better performance in harsh market conditions such as those offered by Zimbabwe's pharmaceutical industry. The study applied regression analysis to the other four components of strategic management yielding similar results confirming this study hypothesises $1-4$ stated. To measure the significance of the relationship between survival, economic prosperity and better performance and the key determinants of strategic management, Pearson's $r$ correlation coefficient was used. Table 4 illustrates the correlation coefficients of all the components/ determinants of strategic management: strategizing $=1$, 0 ; entrepreuring $=1,0$; changing $=0.998$ and investing $=1,0$. The other readings demonstrate a similar pattern confirming the impact of strategic management in Zimbabwe's pharmaceutical sector. $N$ denotes the sample size used (90) on which the correlation coefficient was based.

The significance values denoted by the double asterisk are higher than 0.01 . This significance value indicates that the probability of getting a correlation coefficient this big in a sample of 90 participants if the null hypothesis were true that is, if there was no relationship between these variables was very high. The significance values are below or equals to a standard criterion of 0.05 indicating a 'statistical significant' relationship of the components of strategic management and survival, economic prosperity and better performance (Table 5).

In addition to statistical evidence provided earlier, structured field observations revealed pharmacies in Zimbabwe were increasingly embracing the principles of strategic management. There was logical evidence pointing to the fact that the pharmacists at the helm of these retail health services were mainly driven by intense 
Table 5. The relationship between the determinants of strategic management and market performance.

\begin{tabular}{|c|c|c|c|c|c|}
\hline Dependent variables & & Strategizing & Entrepreneuring & Changing & Investing \\
\hline Importance of planning ahead to (1) survive; (2) economic prosperity; and (3) better performance & $\begin{array}{l}\text { Pearson Correlation } \\
\text { Sig. (2-tailed) } \\
\mathrm{N}\end{array}$ & $\begin{array}{l}1 \\
- \\
90\end{array}$ & $\begin{array}{c}1.000^{*} \\
0.005 \\
90\end{array}$ & $\begin{array}{c}0.998^{*} \\
0.007 \\
90\end{array}$ & $\begin{array}{c}1.000^{* *} \\
0.007 \\
90\end{array}$ \\
\hline $\begin{array}{l}\text { The importance of anticipating the future market conditions to (1) survive; (2) economic prosperity; } \\
\text { and (3) better performance }\end{array}$ & $\begin{array}{l}\text { Pearson Correlation } \\
\text { Sig. (2-tailed) } \\
\mathrm{N}\end{array}$ & $\begin{array}{c}1.000^{*} \\
0.005 \\
90\end{array}$ & $\begin{array}{c}1 \\
90\end{array}$ & $\begin{array}{c}0.990^{*} \\
0.001 \\
90\end{array}$ & $\begin{array}{c}0.997^{* *} \\
0.003 \\
90\end{array}$ \\
\hline $\begin{array}{l}\text { The importance of adjusting or modifying internal business structures to (1) survive; (2) economic } \\
\text { prosperity; and (3) better performance }\end{array}$ & $\begin{array}{l}\text { Pearson Correlation } \\
\text { Sig. (2-tailed) } \\
N\end{array}$ & $\begin{array}{c}0.998^{*} \\
0.007 \\
90\end{array}$ & $\begin{array}{c}0.990^{*} \\
0.010 \\
90\end{array}$ & $\begin{array}{l}1 \\
90\end{array}$ & $\begin{array}{c}0.997^{* *} \\
0.003 \\
90\end{array}$ \\
\hline $\begin{array}{l}\text { The importance of making the right resource investment decisions to (1) survive; (2) economic } \\
\text { prosperity; and (3) better performance }\end{array}$ & $\begin{array}{l}\text { Pearson Correlation } \\
\text { Sig. (2-tailed) } \\
\mathrm{N}\end{array}$ & $\begin{array}{c}1.000^{* *} \\
0.007 \\
90\end{array}$ & $\begin{array}{c}0.997^{\star *} \\
0.003 \\
90\end{array}$ & $\begin{array}{c}0.997^{\star *} \\
0.003 \\
90\end{array}$ & $\begin{array}{l}1 \\
90\end{array}$ \\
\hline
\end{tabular}

commitment and determined perseverance irrespective of the chaotic macro-economic conditions in Zimbabwe. This was clearly displayed by their desire to invest in sophisti-cated resources including computerised inventory systems and learned human capital. A look into the profiles of the key individuals in the pharmacies also showed that they all had attained high levels of qualifications in pharmacy education from abroad. Based on this, it is plausible to infer that the positioning of key individuals within the pharmacies was designed to enhance enhanced organizational performance in a fragile market.

Related to this, there was documentary evidence indicating that these key individuals were embracing the principles of strategic management which proved essential in terms of understanding market variations. Concerning the notion of hedging against the shortages of essential clinical apparatus and prescription drugs often associated with deteriorating markets, the pharmacies established strategic distribution networks with pharmaceutical companies within the Southern African Development Community
(SADC) region including Zambia, South Africa, Swaziland, Mozambique and Botswana. This clearly demonstrated the importance of strategic management and the desire by the pharmacists to 'make it happen' in harsh economic conditions widespread in Zimbabwe's pharmaceutical sector This is consistent with the literature of Fraser and Stupak (2002) who agreed that developing a strategic plan for responding to the business environment is essential for any organi-sation faced with uncertainty. Indeed, the structured field observations showed an existence of wellestablished alliances with pharmaceutical companies mainly originating from South Africa.

It was also recognisable that these business-like relationships (Simba, 2013), though informal, were of paramount importance to retail pharmacies in the study sample. Interestingly, the pharmacists in the research sample appeared to be exploiting the government's 'Black Indigenisation' agenda by developing new markets. Specifically, the pharmacies were experimenting with in-store clinics, wellness programs, health screenings and disease management services in Zimbabwe. This showed that they were considering all feasible options, evaluating their market environment and simulating new ideas with a view to developing an effective plan for going to the market. Arising from this, new insights were developed. Especially, evidence of widespread application of strategic management techniques enhances better market performance and business survival.

\section{New concept formation}

Following the statistical representation and the qualitative interpretation of the results in this study a new business model was proposed. It was however deemed necessary that before outlining the model, some time is spent on briefly explaining the process underpinning its creation. The formation of a new business model is fundamental to what we were trying to address in this research. Precisely, the model helps us to contextualise the social world of the retail pharmacies in Zimbabwe. This is consistent with 
the views of other authors for example; Gerring (2001) who explained that theories are instrumental in social science as they help researchers to make connections between the world people live in, and how they interpret it. The strength of the proposed model lies in its formation - its variables are grounded in the literature and the empirical findings (Glaser and Strauss, 1967; Collier and Mahon, 1993; Mills and Birks, 2014).

To ascertain the applicability of the model the study invite other scholars to test it in different settings either in a developing, emerging or developed nation so as to measure its effectiveness as a blue-print for enhanced market performance (survival, economic prosperity and better performance). The paradox of the political and social-economic conditions in Zimbabwe appears to have spurred pharmaceutical companies, especially retail pharmacies in the City of Harare to apply the principles of strategic management through spontaneous business reconfiguration.

This provided new knowledge suggesting that retail pharmacies in Zimbabwe are employing strategic management techniques to navigate the various operational and business management-related challenges they face. Learning from their processes of going to the market (Piercy, 2002) the study was intrigued by their ingenuity and creativeness. This led to the formation of a new business instrument. Figure 1 diagrammatically illustrates the connectivity of the key determinants of strategic management intended to succour organisations operating in developing, merging or developed nations to prevail in unstable macro-economic conditions. Figure 1 emphasises that paying attention to the specific configurations of the key determinants of strategic management is pivotal to the survival, prosperity and enhanced performance of companies operating in chaotic markets. This was confirmed to be true when we tested the extent to which these determinants influence market performance using regression analysis.

Undoubtedly, harsh market conditions force organizations to be strategic in how they operate. The proposed conceptual model does not, in any way, portray that the process of developing an effective way of going to the market (Piercy, 2002) is a simple procedure but, it rather provides a starting point for organisations in mapping an overarching plan to guarantee survival, economic growth and better performance in ephemeral markets.

Crucially, the framework advances the notion that adopting a strategic management approach by employing strategic reasoning (Mintzberg, 1994), strategic visioning (Johnson et al., 2008), strategic alignment (Thompson, 1999), and strategic venturing (Smit and Trigeorgis, 2004) considerably increases the probability of survival, economic prosperity and better performance of an organisation confronted with challenging market conditions. Clearly, the strength of this model can be directly attributed to the effectiveness of strategic management.
As the study has already alluded to, the framework shows the inter-connectedness of all the constituent components of strategic management. A point to note here is that; a misalignment of these components with the macro-economic environment will have an impact on both current and future market performance especially in turbulent markets irrespective of the fact that an organisation originates from a developing or developed nation. The study accepts that no one can accurately predict the future, but preparing for eventualities can be crucial for any business organisation. Business renewal (De Wit and Meyer, 2014) as projected by the study model has the power to facilitate stability within the organization while enabling sustainable development. From this, it is imperious that business managers of organisations which operate in ephemeral markets use their managerial capabilities to increase the market performance of their firms. More so, they must implement the key components of the strategic management process: strategizing, entrepreneuring, change and investing processes if they are to thrive in such extremely unpredictable market conditions.

\section{DISCUSSION}

A look into the entrepreneurial landscape of Zimbabwe revealed that, to some extent, ingenuity was embraced as the main attribute essential for enhanced market performance in the increasingly deteriorating market conditions (Shumba, 2014). Indeed, such market conditions placed huge operational challenges on organisations requiring them to sense opportunities and threats (Dess et al., 1997) and devise fresh and alternative strategies. In view of this, the study does not take lightly the challenges that retail pharmacies encountered in the process of providing health services in Zimbabwe.

As such, the study argues that strategic management must be recognised as a crucial factor in fostering an effective business model in developing, emerging market or advanced nations. There is universal acknowledgement among scholars that strategy managers enhance the probability of better market performance when they take stock of their sources and rearrange them in ways that are valuable (Lumpkin and Dess, 1996; Miller, 1983; Zahra, 1993; Romer, 2007). Clearly, strategic management is a process widely considered to be a facilitator of economic prosperity, better performance for generating positive externalities in fast-moving business sectors.

Notwithstanding this view, it would be short-sighted to assume that developing a winning formula in unstable macro-economic conditions is a straight forward process. What amounts to strategic management is so complex and extremely challenging. The real challenge in formulating a strategy lies in detecting the subtle discontinuities that may undermine the business in the 
future (Mintzberg, 1994). Arguably, getting the mix of the key components, illustrated in the study nuanced strategic management model presented on Figure 1, and fit them well in internal business processes significantly assists organisations to achieve their corporate goals.

Undoubtedly, it is not easy to predict the future; but the findings of this study provide a useful insight into the management capabilities essential for organisations operating in developing and emerging nations. Ample evidence demonstrated that the retail pharmacies in Zimbabwe were aware of the complexities of operating in unpredictable market conditions, and were determined to 'make it happen'. As such, strategic management was used to integrate their strategic goals and the sequences of their actions (Anderson and Atkins, 2001).

This new development maybe better explained by the observed skills and the awareness of the pharmacists who were responsible for providing the scope and direction of the retail pharmacies. Their well-documented education and training received from abroad appeared to have also provided useful knowledge which was typified by their strategic thinking the study detected in the way they carried out their business operations. Furthermore, their determination and desire to 'make it happen' performed a major role in helping their retail pharmacies to survive a myriad of intractable politically and economically-driven challenges in Zimbabwe. The strategic management manoeuvres evidenced in the retail pharmacies had a direct impact on their performance. The adoption of the principles of strategic management by these pharmacies was mainly driven, to a greater extent, by the characteristics of the industry in which they operated. An important lesson that managers can learn from this research is that; operating in a turbulent market requires organisations to continually renew their internal business processes consistent with the macroeconomic environment.

\section{CONCLUSION}

The study has demonstrated that strategic management as a management process significantly contributes to the survival and better market performance in uncertain markets. It has shown that embracing the principles of strategic management helps to predict future market possibilities while informing the development of appropriate strategies to adopt. The research provides a conceptual framework which, arguably, can be adopted in transient markets which can be found in developing, emerging or developed nations. It was also accepted in this research that strategic management is a process fraught with challenges, but if it is embraced by managers whose organisations are exposed to unpredictable markets the probability that the business will survive, and prosper economically is considerably enhanced.

Although there were no formal strategic management training programs in Zimbabwe. The study provided concrete evidence showing that pharmacists who are currently managing these retail pharmacies are using their management initiatives to minimize the effects of a deteriorating market on their businesses. The strategicminded pharmacists demonstrated a desire to 'make it happen' through their determination and entrepreneurial orientation even if the macro-economic conditions suggested otherwise. Finally, the study can infer that developing nations are increasingly embracing strategic management. As such, entrepreneurial developments of this magnitude should be exposed to the field of management in order to provide valuable knowledge which can be used in managing businesses operating in today's worldwide markets which appear to be in turmoil.

\section{LIMITS OF THE STUDY}

Although the chosen research methodology was deemed appropriate the study is aware of its inherent limits. The fact that the study relied on a survey to generate data for analysis restricted it from obtaining rich data which could have been achieved by conducting qualitative (face-toface) interviews with the key informants. Though the study was mainly interested in generalising the findings to a larger population, a detailed case-by-case analysis would have provided rich data enabling the study to better explain the strategic planning processes of the pharmacies in Zimbabwe. Furthermore, concentrating on pharmacies in the capital city Harare alone allowed the study to remain reasonable in scope (Miles and Huberman, 1994) but it resulted in the reduction of the number of pharmacies that were subjected to the analysis. The bigger the sample, the better would have been the study estimate of $R$ (regression value) generated using a regression technique.

\section{Conflict of Interests}

The authors have not declared any conflict of interests.

\section{REFERENCES}

Al-Shaikh FN (2001). Strategic planning process in developing countries: The case of United Arab Emirates business firms. Manage. Res. News 24(12):7-16.

Anderson AR, Atkins MH (2001). Business strategies for entrepreneurial small firms. Strategic Change 10(6):311-324.

Adner R, Helfat, CE (2003). Corporate effects of dynamic managerial capabilities, Strat. Manage. J. 24:1011-1025

Ansoff IH, Sullivan PA (1993). Optimizing profitability in turbulent environments: A formula for strategic success. Long Range Plan. 26(5):11-23.

Barney JB (1991). Firm resources and sustained competitive advantage. J. Manage. 17(1):99-120

Bellamy C, Perri 6. (2009). Principles of Research Design: A Guide to Methodology in Social Science, Sage Publications Inc., London.

Burns P (2012). Entrepreneurship and Small Business: Start-up, Growth and Maturity, 3rd Edition, Palgrave MacMillan.

CIA World Fact book. (2012). Zimbabwe Economy 2012. Available at: 
http://www.theodora.com/wfbcurrent/zimbabwe/zimbabwe_economy. html.

Collier D, Mahon JE (1993). Conceptual "Stretching" Revisited: Adapting Categories in Comparative Analysis. Am. Polit. Sci. Rev. 87(04):845-855.

Companys YE, McMullen JS (2007). Strategic entrepreneurs at work: the nature, discovery, and exploitation of entrepreneurial opportunities.

Small Bus. Econ. 28(4):301-322.

Creswell JW (2014). Research Design: Qualitative, Quantitative and Mixed Methods Approaches, $4^{\text {th }}$ Edition, International Student Edition, Thousand Oaks: California

De Wit B, Meyer R (2014). Strategy: An International Perspective, $5^{\text {th }}$ Edition, Cengage Learning, EMEA

Dixit A (1992). Investment and hysteresis. J. Econ. Perspect. pp. 107132.

Deloitte, Touché (2013). Doing business in Zimbabwe: The jewel of Africa, Deloitte Studio, Johannesburg, (801321/chr). Available at: http://www2.deloitte.com/content/dam/Deloitte/au/Documents/internat ional-specialist/deloitte-au-aas-doing-business-zimbabwe-13.pdf.

Desai $A B$ (2000). Does strategic planning create value? The stock market's belief, Manage. Decis. 38(10):685-693.

Dess GG, Lumpkin GT, Covin JG (1997). Entrepreneurial Strategy Making and Firm Performance: Tests of Contingency and Configurational Models. Strat. Manage. J. 18(9):677-695.

Eisenhardt KM, Sull DN (2001). Strategy as simple rules. Harvard Bus. Rev. 79(1):107-116.

Field A (2013). Discovering statistics using IBM SPSS statistics. $4^{\text {th }}$ Edition, SAGE Publication, Thousand Oaks: California.

Fraser DL, Stupak RJ (2002). A synthesis of the strategic planning process with the principles of learning, leading and linking. Int. J. Public Adm. 25(9):1199-1220.

Gerring J (2001). Social science methodology: A criterial framework. Cambridge University Press.

Glaser B, Strauss A (1967). The discovery of grounded theory. Weidenfield and Nicolson, London.

Gleick J (1987). Chaos: Making a New Science (Viking Press, New York, NY).

Goncalves H (2009). Proposal of a strategy model planning aligned to the balanced scorecard and the quality environments. TQM J. 21(5):462-472.

Gunther MR, Nerkar A (2004). Real options reasoning and a new look at the R\&D investment strategies of pharmaceutical firms. Strat. Manage. J. 25(1):1-21.

Hamel G, Prahalad CK (1995). Thinking differently. Bus. Quart. 59(4):22-35

Hamel G (1996). Strategy as revolution. Harvard Bus. Rev. pp. 69-71.

Hamel G, Prahalad CK (1989). To revitalize corporate performance, we need a whole new model of strategy. Harvard Bus. Rev. 67(3):63.

Hamel G (2000). Leading the Revolution. Harvard Business School Press: Boston, MA.

Hart SL (1992). An integrative framework for strategy-making processes. Acad. Manage. Rev. 17(2):327-351.

Hitt MA, Ireland RD, Camp SM, Sexton DL (2001). Strategic entrepreneurship: Entrepreneurial strategies for wealth creation. Strat. Manage. J. 22(6):479-492.

Hitt MA, Ireland RD, Sirmon DG, Trahms CA (2011). Strategic entrepreneurship: creating value for individuals, organizations, and society. The Acad. Manage. Perspect. 25(2):57-75.

Ireland RD, Hitt MA, Sirmon DG (2003). Strategic entrepreneurship: The construct and its dimensions. J. Manage. 29(6):963-989.

Johnson G, Scholes K, Whittington R (2006). Exploring Corporate Strategy: text and cases, 6th Edition, Prentice Hall

Johnson G, Scholes K, Whittington R (2008). Exploring Corporate Strategy: text and cases, 7th Edition, Prentice Hall.

Katila R, Chen EL, Piezunka H (2012). All the right moves: How entrepreneurial firms compete effectively. Strat. Entrepr. J. 6(2):116132.

Knight FH (1921). Risk, uncertainty and profit. Washington, DC: Beard Books.

Kirzner IM (1973). Competition and entrepreneurship. Chicago: University of Chicago Press.

Kraus S, Reiche BS, Reschke CH (2007). Implications of strategic planning in SMES for international entrepreneurship research and practice (Published in M. Terziovski (Ed.), Energizing Management through Innovation and Entrepreneurship: Euro. Res. Pract. pp. 110127.

Kogut B, Kulatilaka N (1994). Operating flexibility, global manufacturing, and the option value of a multinational network. Manage. Sci. 40(1):123-139.

Kuratko DF, Audretsch DB (2009). Strategic entrepreneurship: exploring different perspectives of an emerging concept. Entrepr. Theor. Pract. 33(1):1-17.

Kuratko DF (2014). Entrepreneurship: Theory, Process, Practice, $9^{\text {th }}$ Edition, Cengage/South-western Publishers.

Larsen $\mathrm{P}$, Tonge $\mathrm{R}$, Ito $\mathrm{M}$ (1998). The strategic planning process in growing companies. J. Gen. Manage. 24(1):53-68.

Lewis P, Saunders M (2012). Doing research in business and management: An essential guide to planning your project. Financial Times/Prentice Hall.

Lumpkin GT, Dess GG (1996). Clarifying the entrepreneurial orientation construct and linking it to performance. Acad. Manage. Rev. 21(1):135-172.

Markides CC (1999). A dynamic view of strategy. Sloan Manage. Rev. 40(3):55-63.

Mason RB (2007). The external environment's effect on management and strategy: a complexity theory approach. Manage. Decis. 45(1):10-28.

Mazzarol T, Rebound S, Soutar GN (2009). Strategic planning in growth oriented small firms. Int. J. Entrepr. Behav. Res. 15(4):320-345.

Mills J, Birks M (2014). Qualitative Methodology: A practical guide. SAGE Publications, Thousand Oaks: California.

Miller D (1983). The correlates of entrepreneurship in three types of firms. Manage. Sci. 29(7):770-791.

Miles MB, Huberman AM (1994). Qualitative data analysis: An expanded sourcebook. $2^{\text {nd }}$ Edition, SAGE Publications, Thousand Oaks: London.

Mintzberg H (1994). 'The fall and rise of strategic planning', Harvard Business Review, January-February 1994. pp. 107-114.

Mintzberg H (1987). Crafting strategy, Harvard Business School Press.

Mintzberg H, Waters JA (1985). Of strategies, deliberate and emergent. Strat. Manage. J. 6(3):257-272.

Morris MH, Kuratko DF, Covin JG (2008). Corporate Entrepreneurship and Innovation, Entrepreneurial Development within Organizations, $2^{\text {nd }}$ Edition' Thomson South-Western.

Mosakowski E (1998). Entrepreneurial resources, organizational choices, and competitive outcomes. Organ. Sci. 9(6):625-643.

Mullins LJ (2013). Management and Organisational Behaviour, $10^{\text {th }}$ Edition, Pearson Education Ltd, Essex: London

Mullins LJ (2005). Management and Organisational Behaviour, $7^{\text {th }}$ Edition, Pearson Education Ltd, Essex: London.

Normann R, Ramirez R (1993). From Value Chain to Value Constellation: Designing interactive strategy. Harvard Bus. Rev. pp. 65-77

Penrose E (1959). The Theory of the Growth of the Firm, Oxford University Press, Oxford.

Picken JC, Dess GG (1996). The Seven Traps of Strategic Planning November 1996. Inc.: pp. 99-103.

Piercy NF (2002). Research in marketing: teasing with trivia or risking relevance? Eur. J. Market. 36(3):350-363.

Prahalad CK, Hamel G (1989). "Strategic intent", Harvard Bus. Rev. pp. 63-76

Romer P (2007). 'Economic Growth', in David R. Henderson (ed.) Fortune Encyclopaedia of Economics. New York: Time Warner Books. Available at: http://www.stanford. edu/ promer/EconomicGrowth.pdf.

Sandada M, Pooe D, Dhurup M (2014). Strategic planning and its relationship with business performance among small and medium enterprises in South Africa, Int. Bus. Econ. Res. J. 13(3):659-670

Santos FM, Eisenhardt KM (2009). Constructing markets and shaping boundaries: Entrepreneurial power in nascent fields. Acad. Manage. J. 52(4):643-671.

Sarasvathy SD (2001). Effectual reasoning in Entrepreneurial decision making: Existence and Bounds. Acad. Manage. Proc. (1):D1-D6).

Scarborough NM (2014). Essentials of Entrepreneurship and Small 
Business Management (7th ed.), Pearson Education, Inc.: Upper Saddle River, NJ.

Shane S (2000). Prior knowledge and the discovery of entrepreneurial opportunities. Organ. Sci. 11(4):448-469.

Shane S, Venkataraman S (2000). The promise of entrepreneurship as a field of research. Acad. Manage. Rev. 25(1):217-226.

Shumba V (2014). The journey towards productive entrepreneurship: A theoretical review of the entrepreneurial landscape in Zimbabwe. Int. J. Econ. Comm. Manage. 2(7):1-12.

Simba A (2013). 'The role of global R\&D networks in generating social capital for born-global bio-tech firms: a multi-case approach,' Int. J. Entrepr. Small Bus. 20(3):342-362.

Smit HT, Trigeorgis L (2004). Quantifying the strategic option value of technology investments. Montreal: 8th Annual International Real Options Theory.

Singer S, Alpeza M, Balkic M (2009). Corporate Entrepreneurship: is entrepreneurial behaviour possible in a large company. In International Conference on Entrepreneurship and Innovation PODIM, March, 2009.

Stacey RD (1995). The science of complexity: An alternative perspective for strategic change processes. Strat. Manage. J. 16(6):477-495.
Teece DJ, Pisano G, Shuen A (1997). Dynamic capabilities and strategic management. Strat. Manage. J. 18(7):509-533.

Thompson JL (1999). A strategic perspective of entrepreneurship. Int. J. Entrepr. Behav. Res. 5(6):279-296.

Wiltbank R, Read S, Dew N, Sarasvathy SD (2009). Prediction and control under uncertainty: Outcomes in angel investing. J. Bus. Vent. 24(2):116-133.

Zahra SA, Covin JG (1995). Contextual influences on the corporate entrepreneurship-performance relationship: A longitudinal analysis. J. Bus. Vent. 10(1):43-58. 